Published in final edited form as:

Trends Cardiovasc Med. 2017 August ; 27(6): 420-425. doi:10.1016/j.tcm.2017.02.005.

\title{
The role of cardiac rehabilitation in patients with heart disease $\hbar$
}

\author{
Sean R. McMahon a ${ }^{\star}{ }^{\star}$, Philip A. Ades ${ }^{\mathrm{a}}$, and Paul D. Thompson ${ }^{\mathrm{b}}$ \\ ${ }^{a}$ Cardiology Unit and Cardiovascular Research Institute, Department of Medicine, Lamer College \\ of Medicine at the University of Vermont, Burlington, VT, USA \\ bHeart and Vascular Institute, Department of Medicine, Hartford HealthCare, Hartford, CT, USA
}

\begin{abstract}
Cardiac rehabilitation is a valuable treatment for patients with a broad spectrum of cardiac disease. Current guidelines support its use in patients after acute coronary syndrome, coronary artery bypass grafting, coronary stent placement, valve surgery, and stable chronic systolic heart failure. Its use in these conditions is supported by a robust body of research demonstrating improved clinical outcomes. Despite this evidence, cardiac rehabilitation referral and attendance remains low and interventions to increase its use need to be developed.
\end{abstract}

\section{Keywords}

Cardiac rehabilitation; Cardiovascular disease

\section{Introduction}

Cardiac rehabilitation (CR) has evolved from exercise only into a comprehensive program that also addresses other cardiovascular disease risk factors and provides education and social support [1]. CR classically consists of three phases. Phase I refers to inpatient rehabilitation during the index hospitalization. Due to the increasingly shorter durations of hospital stay, phase I CR has become less formalized. Phase II refers to physician supervised, outpatient monitored physical activity during the 4 months after discharge. Patients usually undergo up to 36 sessions in a graduated exercise program. Thereafter, patients may continue into phase III, which is an enduring unmonitored exercise program. $\mathrm{CR}$ programs also provide nutritional, psychological and smoking cessation counseling, as well as lipid and blood pressure management. Medicare and most insurance carriers provide coverage for this service after acute coronary syndrome, percutaneous coronary intervention (PCI), coronary artery bypass grafting (CABG), valve surgery, and chronic stable heart failure with reduced ejection fraction (HFrEF) [2]. The American Heart Association (AHA) and American College of Cardiology (ACC) consider CR a Class I indication for these conditions $[3,4]$.

\footnotetext{
خ Paul D. Thompson, MD: no relevant conflicts.

"Correspondence to: Larner College of Medicine, University of Vermont, UVMMC, McClure 1 Cardiology, 111 Colchester Avenue, Burlington, VT 05401, USA. S_R_McMahon@yahoo.com (S.R. McMahon).
} 
The exercise prescription at $\mathrm{CR}$ centers optimally starts with a pre-exercise-training, symptom limited, exercise tolerance test. Thereafter, workouts typically consist of a brief warm up period, followed by supervised individualized aerobic exercise, and a brief cool down phase. The aerobic exercise consists of 20-60 min workouts 3-5 days a week at 50$80 \%$ of maximal exercise capacity [1]. Relatively recent data suggest that high intensity interval training (HIIT) produces larger and more rapid increases in exercise capacity [5-7]. A trial of 27 patients with stable ischemic cardiomyopathy randomized to either moderate continuous training at $70 \%$ of their max predicted heart rate or to HUT at $95 \%$ peak heart rate or to a exercise-advise-only control group demonstrated a 46 vs $14 \%(\mathrm{p}<0.001)$ increase in peak oxygen consumption $\left(\mathrm{VO}_{2 \mathrm{MAX}}\right)$ in the HUT vs continuous training group [5]. Higher VO2MAX has been associated with lower mortality rates in patients with coronary artery disease (CAD) [8]. HUT also improved endothelial function, reversed left ventricular remodeling, and increased ejection fraction more than continuous training [5]. Similar superior improvements have been noted in other studies [6,7]. Yet it should not be forgotten that the favorable meta-analyses of CR showing reductions in total mortality and rehospitalizations were based upon the utilization of moderate intensity exercise [9].

\section{The role of exercise training}

Many of the benefits of CR are derived from exercise training. Exercise training increases $\mathrm{VO}_{2 \mathrm{MAX}}$ and endurance capacity or the ability to maintain physical activity for extended periods of time [5]. Exercise training has multiple other potentially beneficial effects including improving endothelial function [5,10], myocardial flow reserve [11] reducing smoking, body weight, blood lipids, and blood pressure [12]. Exercise training has even been shown to reduce the progression of coronary atherosclerosis in patients with known CAD [11].

CR also reduces depression and anxiety and increases quality of life in cardiac patients [13]. Depression is associated with higher mortality, up to fourfold higher in one study of depressed cardiac patients [14]. Depression symptoms and mortality decreased by $63 \%$ and $73 \%$ among depressed patients after CR compared to non-participants $(\mathrm{p}<0.001)$ [14].

\section{Coronary artery disease (CAD)}

$\mathrm{CAD}$ is the most common referral diagnosis to $\mathrm{CR}$ centers. Exercise training or $\mathrm{CR}$ in patients with CAD increases exercise tolerance and quality of life [5,6,15-17], decreases angina [18],ischemia [19], subsequent hospitalizations [15,17], and mortality [9,15].

The AHA/ACC recommends the referral of patients after myocardial infarction (MI) or coronary revascularization and those with stable angina to CR [4] because multiple metaanalysis have demonstrated that $\mathrm{CR}$ reduces mortality in patients with CAD [9,15,20,21]. A meta-analysis of 63 randomized clinical trials dating from 1974 through 2014 including 14,486 patients documented that CR, compared to no-exercise control reduced cardiovascular mortality (10.4 vs $7.6 \%$, CI $0.64-0.86$, number needed to treat (NNT): 37 ) in patients with CAD. Hospital admissions were also reduced at one year ( 31 vs $26 \%$, CI 0.70 
0.96, NNT: 22). Health related quality of life increased and the cost of health care resources decreased [15].

$\mathrm{CR}$ benefits patients with CAD regardless of the referral diagnosis. Exercise training has long been known to reduce symptoms in patients with angina pectoris and CR may be as effective as PCI at least in the short term. Selected male patients with stable angina $(\mathrm{n}=101)$ randomized to PCI or CR demonstrated increased exercise capacity and reduced coronary events at 12 months in the CR vs control group [17]. Exercise training was associated with a higher event free survival ( $88 \%$ vs $70 \%, \mathrm{p}=0.023$ ), increased $\mathrm{VO}_{2 \mathrm{MAX}}(+16 \%, \mathrm{p}<0.001)$, and lower cost ( $\$ 3429$ vs $\$ 6956$ Canadian currency).

CR also benefits patients after emergent, urgent or elective PCI. Patients $(n=2395)$ referred to CR after emergent (32\%), urgent (42\%), or elective (26\%) PCI and followed for a mean of 6.3 years experienced a $46 \%$ relative reduction in all-cause mortality (CI 0.41-0.71, NNT: 34) (Fig. 1) [22]. This was independent of age, sex, or PCI setting (elective vs non-elective). Recurrent MI and repeat PCI, however, were not different between the groups. Similarly, 118 patients randomized to $\mathrm{CR}$ or usual care after PCI increased their $\mathrm{VO}_{2 \mathrm{MAX}}(+26 \%, \mathrm{p}<$ $0.001)$ and quality of life $(+26.8 \%, \mathrm{p}=0.001)$ and experienced lower rates of cardiac events (11.9 vs $32.2 \%, \mathrm{p}=0.008)$, and hospital readmissions rates $(18.6$ vs $46 \%, \mathrm{p}<0.001)$ after six months. The rate of angiographic restenosis was similar, but the CR patients had less stenosis $(29.7 \%, \mathrm{p}=0.045)$ and less evidence of myocardial ischemia by nuclear imaging $(19 \%, \mathrm{p}<0.001)$, although this study did precede the widespread use of drug eluting stents [19].

CR has been evaluated extensively in patients referred after acute MI. A meta-analysis of 36 randomized control trials including 6111 patients after MI demonstrated a 36\% reduction in cardiac deaths (confidence interval (CI) $0.46-0.88$ ), $26 \%$ reduction in total mortality (CI $0.85-0.95$ ), and a $47 \%$ reduction in reinfarction (CI 0.38-0.76) [12].

$\mathrm{CR}$ also reduces cardiac events, hospital readmissions and mortality after CABG. An observational trial of 846 patients after CABG, $69 \%$ of whom attended CR, evaluated after a mean follow-up of 9 years reported a $46 \%$ relative risk reduction (RRR) and $12.7 \%$ absolute risk reduction of all-cause mortality with a number needed to treat of 8 (CI 0.40-0.74) [23]. These findings were independent of age, sex, prior myocardial infarction, or diabetes. Another observational study of 3975 patients after CABG demonstrated an all-cause mortality reduction of $20 \%$ with phase $1 \mathrm{CR}$ and $40 \%$ with phase 2 CR [24]. Both studies used the propensity score matching method to account for inherent selection bias.

Despite the clear benefit of CR to patients with CAD, referral rates and rates of participation remain low. In one study, whereas $62 \%$ of patients above age 65 were referred to CR after MI, only $33 \%$ of these attended one session [25]. Rates are even lower among women and minorities [26]. The reasons for low referral rates are not clear, but include transportation problems, lack of insurance, financial need to return to work, and other barriers. It is also noted that many physicians underestimate the value of exercise training, risk management and psychosocial support in CAD patients and without physician referral, participation is unlikely [27]. 


\section{Valvular heart disease}

The evidence supporting $\mathrm{CR}$ for $\mathrm{CAD}$ patients is robust, whereas there are less data on $\mathrm{CR}$ for patients after valve surgery. An attempt to perform a meta-analysis of randomized, controlled trials of $\mathrm{CR}$ after valve surgery found only 2 trials worthy of inclusion. There was an increase in exercise capacity with CR (standard mean difference: $-0.47 \mathrm{~kJ}, \mathrm{CI}$ $-0.81-0.13)$ [28], but too few participants $(\mathrm{N}=148)$ to evaluate other outcomes. A retrospective review of patients participating in CR after valve surgery observed an increase in quality of life, which is congruent with an increase in $\mathrm{VO}_{2 \mathrm{MAX}}(\mathrm{r}=0.62, \mathrm{p}<0.05)$ [29].

Data on transcatheter aortic valve replacement (TAVR) and CR have been limited to observational trials demonstrating increased exercise capacity and quality of life [30,31]. A pilot trial [32] randomized 30 TAVR patients to eight weeks of supervised endurance and resistance exercise training or standard care. Average $\mathrm{VO}_{2 \mathrm{MAX}}$ increased $3.7 \mathrm{ml} / \mathrm{min} / \mathrm{kg}$ $(\mathrm{p}=0.007)$ more in the exercise vs. control group. Muscle strength and quality of life $(+16.8 \%, \mathrm{p}=0.009)$ also increased more in the exercise trained group compared to control.

\section{Heart failure}

Medicare initiated coverage of CR for patients with HFrEF in 2014. Patients are eligible for coverage if they have stable heart failure with a left ventricular ejection fraction (LVEF) < $35 \%$ and New York Heart Association (NYHA) class II to IV symptoms despite at least 6 weeks of appropriate medical management [33].

The exercise training meta-analysis of trials in patients with chronic heart failure or ExTraMatch study provided evidence that exercise training benefits patients with heart failure [34]. HFrEF patients randomized to exercise experienced a $45 \%$ reduction in mortality (CI -8 to $54 \%, \mathrm{p}=0.015$ ). Only 17 patients needed to be treated for 2 years to save a life. The combined endpoint of death or hospital admissions also decreased 38\% in the exercise training group (hazard ratio (HR) 0.72, CI 0.56-0.93) (Fig. 2).

Medicare approval for CR reimbursement, however, was primarily based on the results of HF-ACTION or the Heart Failure: A Controlled Trial Investigating Outcomes of Exercise Training study. This trial randomized 2331 patients to exercise training or standard therapy [35]. Exercise training reduced the primary endpoint, all cause mortality or hospitalization, by $11 \%$ ( $\mathrm{p}=0.03$ ) after adjustment for the prespecified baseline confounders of atrial fibrillation/flutter, psychological depression, ejection fraction, and exercise capacity (Fig. 3). The secondary endpoint of CV mortality or CHF hospitalizations was also reduced by $9 \%$ (p $=0.03$ ) after adjustment for baseline variables. Three-year mortality was similar in the two arms of the study. This trial has been strongly criticized because the increase in $\mathrm{VO}_{2 \max }$ was only $4 \%$ among the exercise training participants.

There are few studies that have examined the effect of exercise training in patients with ventricular assist devices. The REHAB-VAD or Cardiac Rehabilitation Improves Functional Capacity and Patient -Reported Health Status in Patients With Continuous Flow Left Ventricular Assist Devices trial demonstrated increased functional capacity and health status in 21 subjects randomized to $\mathrm{CR}$ versus usual care. The $\mathrm{CR}$ group experienced increases in 
quality of life $(30 \%, \mathrm{p}=0.018)$ and treadmill time $(27 \%, \mathrm{p}=0.001)$ compared to control. The $\mathrm{CR}$ group also improved $\mathrm{VO}_{2 \max }$ by $10 \%(\mathrm{p}=0.007)$. Six minute walk, ventilatory threshold, submaximal exercise heart rate, and heart rate at one minute of recovery also only improved within the CR group.

Patients with heart failure with preserved ejection fraction (HFpEF) comprise an increasing proportion of the HF population. CR for this patient population is not presently reimbursed by third party payers or endorsed by clinical guidelines. An exercise training study of 54 patients with cardiomyopathy randomized to exercise training vs control demonstrated a reduction in left ventricular diastolic stiffness in the exercise training group suggesting that CR improves diastolic function [36]. A trial of 64 patients with HFpEF and NYHA class IIIII symptoms randomized to exercise training or control, (Ex-DHF or Exercise Training in Diastolic Heart Failure) demonstrated that exercise training improves both quality of life and exercise capacity in patients with $\mathrm{HFpEF}$ [37]. $\mathrm{VO}_{2 \mathrm{MAX}}$ increased by $21 \%(\mathrm{p}<0.001)$ and the mean decrease in E/e' was $3.2(\mathrm{p}<0.001)$ in the exercise trained group. Subjects who decreased E/e' experienced a $38 \%$ increase of $\mathrm{VO}_{2 \max }$ and a $50 \%$ improvement of in their physical functioning.

\section{Cardiac transplant}

Cardiac transplant patients represent a small portion of those referred for cardiac rehabilitation, but these patients are typically profoundly deconditioned due to their pre transplant severe heart failure, prolonged hospital course, and side effects of immunologic therapies. Additionally, the heart is initially denervated in cardiac transplant patients reducing their physiologic response to exercise. Peak $\mathrm{VO}_{2}$ in patients post cardiac transplant recipients is reportedly $70 \%$ less than age matched controls [38].

In 1988, a trial assessed the effectiveness of a two-year exercise program in 36 orthotopic cardiac transplant patients [38]. $\mathrm{VO}_{2 \max }$ increased 27\%, $\mathrm{p}<0.001$ with exercise training. Similarly, a trial of 27 cardiac transplant recipients randomized to $\mathrm{CR}$ also noted a 4.4 $\mathrm{ml} / \mathrm{kg} / \mathrm{min}(49 \%)$ increase in $\mathrm{VO}_{2 \max }$ at 6 months with exercise training vs a $1.9 \mathrm{ml} / \mathrm{kg} / \mathrm{min}$ (18\%) increase in the control group $(\mathrm{p}=0.01)$ [39].

\section{Challenges and future directions}

Available data and guidelines strongly support the role of comprehensive CR in patients with heart disease. Patients benefit from decreased mortality, morbidity, disability, and increased quality of life. CR patients also benefit from reduced hospitalizations, an increasingly important measure as healthcare moves towards a capitated environment. Despite this, only $14 \%$ of patients after AMI and $31 \%$ in patients after CABG participate in CR [40]. Future studies should focus on how to include more cardiac patients in CR. Indeed, The Centers for Disease Control and Medicare have teamed up to expand CR participation as part of the "Million Hearts" program [41]. Efforts are needed to overcome the social, economic, and practice behaviors to referral, enrollment, and adherence to CR such that the clinical benefits are attained. In view of a geographic non-availability of CR programs for some patients, 
hybrid home CR programs are also being developed [41]. Studies are also needed to evaluate the utility of CR in patients after valve surgery and TAVR as well as in patients with HFpEF.

\section{Conclusions}

$\mathrm{CR}$ is a valuable treatment for a broad spectrum of patients with heart disease. It use is supported by a robust body of research demonstrating improvements in cardiopulmonary fitness, psychological factors, and quality of life and reductions in morbidity and mortality. It is also an excellent strategy for reducing hospital readmissions. Despite this evidence, the value of CR is underappreciated and underutilized by many clinicians to the detriment of patient outcomes.

\section{Acknowledgments}

Disclosures: Sean R. McMahon, MD: None. Philip A. Ades, MD: supported in part by Center of Biomedical Research Excellence Award P20GM103644 from the National Institute of General Medical Sciences.

\section{References}

1. Balady GJ, Williams MA, Ades PA, Bittner V, Comoss P, Foody JA, et al. American Heart Association Exercise, Cardiac Rehabilitation, and Prevention Committee; Council on Clinical Cardiology; Councils on Cardiovascular Nursing, Epidemiology and Prevention, and Nutrition, Physical Activity, and Metabolism; American Association of Cardiovascular and Pulmonary Rehabilitation. Core components of cardiac rehabilitation/secondary prevention programs: 2007 update: a scientific statement from the American Heart Association Exercise, Cardiac Rehabilitation, and Prevention Committee, the Council on Clinical Cardiology; the Councils on Cardiovascular Nursing, Epidemiology and Prevention, and Nutrition, Physical Activity, and Metabolism; and the American Association of Cardiovascular and Pulmonary Rehabilitation. J Cardiopulm Rehabil Prev. 2007; 27:121-129. [PubMed: 17558191]

2. Medicare.gov. cited 2016 December 21. Available from: <https://www.medicare.gov/coverage/ cardiac-rehab-programs.html〉

3. Leon AS, Franklin BA, Costa F, Balady GJ, Berra KA, Stewart KJ, Thompson PD, Williams MA, Lauer MS. Cardiac rehabilitation and secondary prevention of coronary heart disease: an American Heart Association Scientific Statement from the Council on Clinical Cardiology (Subcommittee on Exercise, Cardiac Rehabilitation, and Prevention) and the Council on Nutrition, Physical Activity, and Metabolism (Subcommittee on Physical Activity), in Collaboration With the American Association of Cardiovascular and Pulmonary Rehabilitation. Circulation. 2005; 111:396-376.

4. Balady GJ, Ades PA, Bittner VA, Franklin BA, Gordon NF, Thomas RJ, Tomaselli GF, Yancy CW. Referral, enrollment and delivery of cardiac rehabilitation/secondary prevention programs at clinical centers and beyond: a presidential advisory from the American Heart Association. Circulation. 2011; 124:2951-2960. [PubMed: 22082676]

5. Wisløff U, Støylen A, Loennechen JP, Bruvold M, Rognmo Ø, Haram PM, et al. Superior cardiovascular effect of aerobic interval training versus moderate continuous training in heart failure patients. Circulation. 2007; 115:3086-3094. [PubMed: 17548726]

6. Keteyian SJ, Hibner BA, Bronsteen K, Kerrigan D, Aldred HA, Reasons LM, et al. Greater improvement in cardiorespiratory fitness using higher-intensity interval training in the standard cardiac rehabilitation setting. J Cardiopulm Rehabil Prev. 2014; 34(2):98-105. [PubMed: 24531203]

7. Moholdt T, Aamot IL, Granøien I, Gjerde L, Myklebust G, Walderhaug L, et al. Aerobic interval training increases peak oxygen uptake more than usual care exercise training in myocardial infarction patients: a randomized controlled study. Clin Rehabil. 2012; 26(1):33-44. [PubMed: 21937520] 
8. Keteyian SJ, Brawner CA, Savage PD, Ehman JK, Schairer J, Divine G, et al. Peak aerobic capacity predicts prognosis in patients with coronary heart disease. Am Heart J. 2008; 156(2):292-300. [PubMed: 18657659]

9. Heran BS, Chen JM, Ebrahim S, Moxham T, Oldridge N, Rees K, et al. Exercise-based cardiac rehabilitation for coronary heart disease. Cochran Database Syst Rev. 2011; 6:7.

10. Edwards DG, Schofield RS, Lennon SL, Pierce GL, Nichols WW, Braith RW. Effect of exercise training on endothelial function in men with coronary artery disease. Am J Cardiol. 2003; 93(5): $617-620$.

11. Gielen S, Hambrecht R. Effects of exercise training on vascular function and myocardial perfusion. Cardiol Clin. 2001; 9:357-368.

12. Lawler PR, Filion KB, Eisenberg MJ. Efficacy of exercise based cardiac rehabilitation post myocardial infarction: a systematic review and meta analysis of randomized controlled trials. Am Heart J. 2011; 162:571-584. [PubMed: 21982647]

13. Milani RV, Lavie CJ, Cassidy MM. Effects of cardiac rehabilitation and exercise training programs on depression in patients after major coronary events. Am Heart J. 1996; 132:726-732. [PubMed: 8831359]

14. Milani RV, Lavie CJ. Impact of cardiac rehabilitation on depression and its associated mortality. Am J Med. 2007; 120(9):799-806. [PubMed: 17765050]

15. Anderson L, Oldridge N, Thompson DR, Zwisler AD, Rees K, Martin N, Taylor RS. Exercise based cardiac rehabilitation for coronary heart disease. J Am Col Cardiol. 2016; 67(1):1-12.

16. Rogers MA, Yamamoto C, Hagberg JM, Holloszy JO, Ehsani AA. The effect of 7 years of intense exercise training on patients with coronary artery disease. J Am Coll Cardiol. 1987; 10:321-326. [PubMed: 3598003]

17. Hambrecht R, Walther C, Mobius-Winkler S, Gielen S, Linke A, Conradi K, Erbs S, Kluge R, Kendziorra K, Sabri O, Sick P, Schuler G. Percutaneous coronary angioplasty compared with exercise training in patients with stable coronary artery disease: a randomized trial. Circulation. 2004; 109:1371-1378. [PubMed: 15007010]

18. Ades PA, Grunvald MH, Weiss RM, Hanson JS. Usefulness of myocardial ischemia as predictor of training effect in cardiac rehabilitation after acute myocardial infarction or coronary artery bypass grafting. Am J Cardiol. 1989; 63(15):1032-1036. [PubMed: 2784932]

19. Belardinelli R, Paolini I, Cianci G, Piva R, Georgiou D, Purcaro A. Exercise training intervention after coronary angioplasty: the ETICA trial. J Am Coll Cardiol. 2001; 37(7):1891-1900. [PubMed: 11401128]

20. Taylor RS, Brown A, Ebrahim S, Jolliffe J, Noorania H, Rees K, Skidmore B, Stone JA, Thompson DR, Oldridge N. Exercise-based rehabilitation for patients with coronary heart disease: a systematic review and meta-analysis of randomized controlled trials. Am J Med. 2004; 116(10): 682-692. [PubMed: 15121495]

21. Oldridge NB, Guyatt GH, Fischer ME, Rimm AA. Cardiac rehabilitation after myocardail infarction: combined experience of randomized clinical trials. JAMA. 1988; 260:945-950. [PubMed: 3398199]

22. Goel K, Lennon RJ, Tilbury T, Squires RW, Thomas RJ. Impact of cardiac rehabilitation on mortality and cardiovascular events after percutaneous coronary intervention in the community. Circulation. 2011; 123:2344-2352. [PubMed: 21576654]

23. Pack QR, Goel K, Lahr BD, Greason KL, Squires RW, Lopez-Jimenez L, et al. Participation in cardiac rehabilitation and survival following coronary artery bypass graft surgery. Circulation. 2013; 128:590-597. [PubMed: 23836837]

24. Lee JY, Han S, Ahn JM, Park DW, Kang SJ, Lee SW, et al. Impact of participation in phase I and phase II cardiac rehabilitation on long term survival after coronary artery bypass graft surgery. Int J Cardiol. 2014; 176(3):1429-1432. [PubMed: 25156848]

25. Doll JA, Hellkamp A, Ho M. Participation in cardiac rehabilitation programs among older patients after acute myocardial infarction. JAMA. 2015; 175(10):1700-1702.

26. Valencia HE, Savage PD, Ades PA. Cardiac rehabilitation participation in un-derserved populations. J Cardiopulm Rehab. 2011; 31(4):203-210. 
27. Ades PA, Waldmann ML, McCann WJ, Weaver SO. Predictors of cardiac rehabilitation participation in older coronary patients. Arch Intern Med. 1992; 152(5):1033-1035. [PubMed: 1580707]

28. Sibilitz KL, Berg SK, Tang LH, Risom SS, Gluud C, Lindschou J, Kober L, Hassager C, Taylor RS. Exercise-based cardiac rehabilitation for adults after valve surgery. Cochran Database Syst Rev. 2016; 3

29. Ueshima K, Kamata J, Kobayashi N, Saito M, Sato S, Kawazoe K, Hiramori K. Effects of exercise training after open heart surgery on quality of life and exercise tolerance in patients with mitral regurgitation or aortic regurgitation. Jpn Heart J. 2004; 45:789-797. [PubMed: 15557720]

30. Voller H, Salzwedel A, Nitardy A, Buhlert H, Treszl A, Weqscheider K. Effect of cardiac rehabilitation on functional and emotional status in patients after transcatheter aortic-valve implantation. Eur J Prev Cardiol. 2015; 22(5):568-574. [PubMed: 24577878]

31. Zanettini R, Gatto G, Mori L, Pozzoni MB, Pelenghi S, Martinelli L, Klugmann S. Cardiac rehabilitation and mid-term follow up after transcatheter aortic valve implantation. J Geriatr Cardiol. 2014; 11(4):279-285. [PubMed: 25593575]

32. Pressler A, Christle JW, Lechner B, Grabs V, Haller B, Hettich I, et al. Exercise training improves exercise capacity and quality of life after transcatheter aortic valve implantation: a randomized pilot trial. Am Heart J. 2016; 182:44-53. [PubMed: 27914499]

33. Centers for Medicare and Medicaid Services. CMS.gov. 2014. cited 2016 December 21. Available from: (https://www.cms.gov/medicare-coverage-database/details/nca-decision-memo.aspx? NCAId $=270$ )

34. Piepoli MF, Davos C, Francis DP, Coats AJ. Exercise training meta-analysis of trials in patients with chronic heart failure (ExTraMATCH). BMJ. 2004; 328(189):1-7. [PubMed: 14703521]

35. O'Connor CM, Whellan DJ, Lee KL, et al. Efficacy and safety of exercise training on patients with chronic heart failure: HF-ACTION randomized controlled trial. JAMA. 2009; 301(14):1439-1450. [PubMed: 19351941]

36. Malfatto G, Branzi G, Osculati G, et al. Improvement in left ventricular diastolic stiffness induced by physical training in patients with dilated cardiomyopathy. J Card Fail. 2009; 15:327-333. [PubMed: 19398081]

37. Edelmann F, Gelbrich G, Dungen HD, Frohling S, Wachter R, Stahrenberg R, Binder L, et al. Exercise training improves exercise capacity and diastolic function in patients with heart failure with preserved ejection fraction: results of the EX-DHF (Exercise Training in Diastolic Heart Failure) pilot study. JACC. 2011; 58(17):1780-1791. [PubMed: 21996391]

38. Kavanagh T, Yacoub MH, Mertens DJ, Kennedy J, Campbell RB, Sawyer P. Cardiorespiratory responses to exercise training after orthotopic cardiac transplantation. Circulation. 1988; 77:162171. [PubMed: 3275506]

39. Kobashigawa JA, Leaf DA, Lee N, Gleeson MP, Liu H, Hamilton MA, et al. A controlled trial of exercise rehabilitation after heart transplantation. N Eng J Med. 1999; 340:272-277.

40. Suaya JA, Shepard DS, Normand SLT, Ades PA, Prottas J, Stason WB. Use of cardiac rehabilitation by medicare beneficiaries after myocardial infarction or coronary artery bypass surgery. Circulation. 2007; 116:1653-1662. [PubMed: 17893274]

41. Ades PA, Keteyian SJ, Wright JS, Hamm LF, Lui K, Newlin K, et al. Increasing cardiac rehabilitation participation from $20 \%$ to $70 \%$ : a road map from the million hearts cardiac rehabilitation collaborative. Mayo Clin Proc. 2016:1-9. [PubMed: 26763508] 


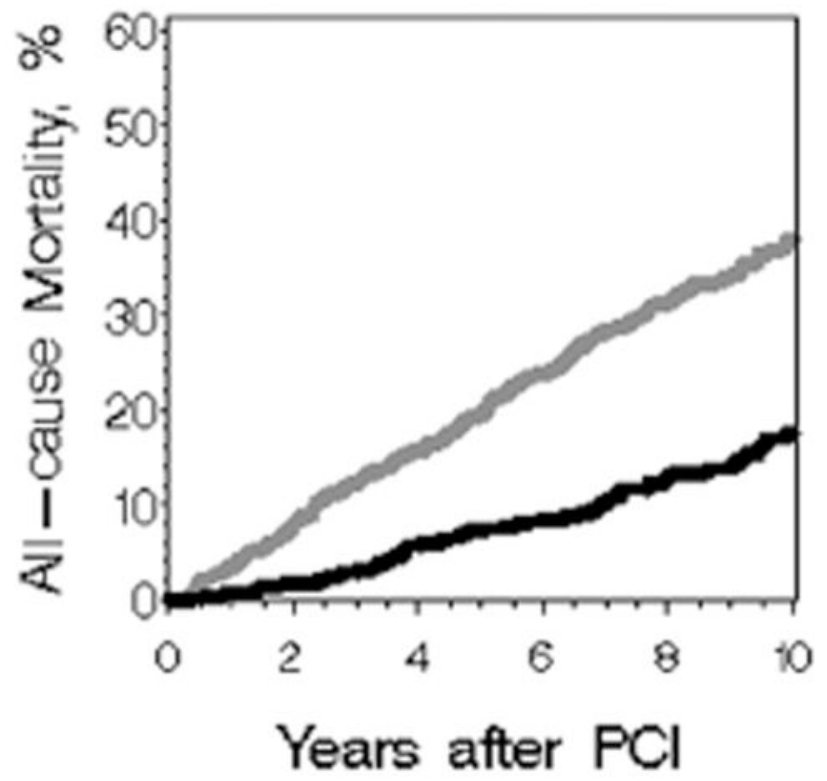

\section{$\begin{array}{lllllll}\text { No Renab } & 1224 & 982 & 701 & 479 & 321 & 202\end{array}$} $\begin{array}{llllll}\text { Carciac Rehab } 785 & 600 & 527 & 377 & 250 & 131\end{array}$

Fig. 1.

Effect of cardiac rehabilitation on mortality after percutaneous intervention. (Kaplan-Meier curve showing the association between cardiac rehabilitation (dark line) and all-cause mortality in patients after elective (26\%), urgent (42\%), or emergent (32\%) percutaneous coronary intervention. Reproduced from [22].) 

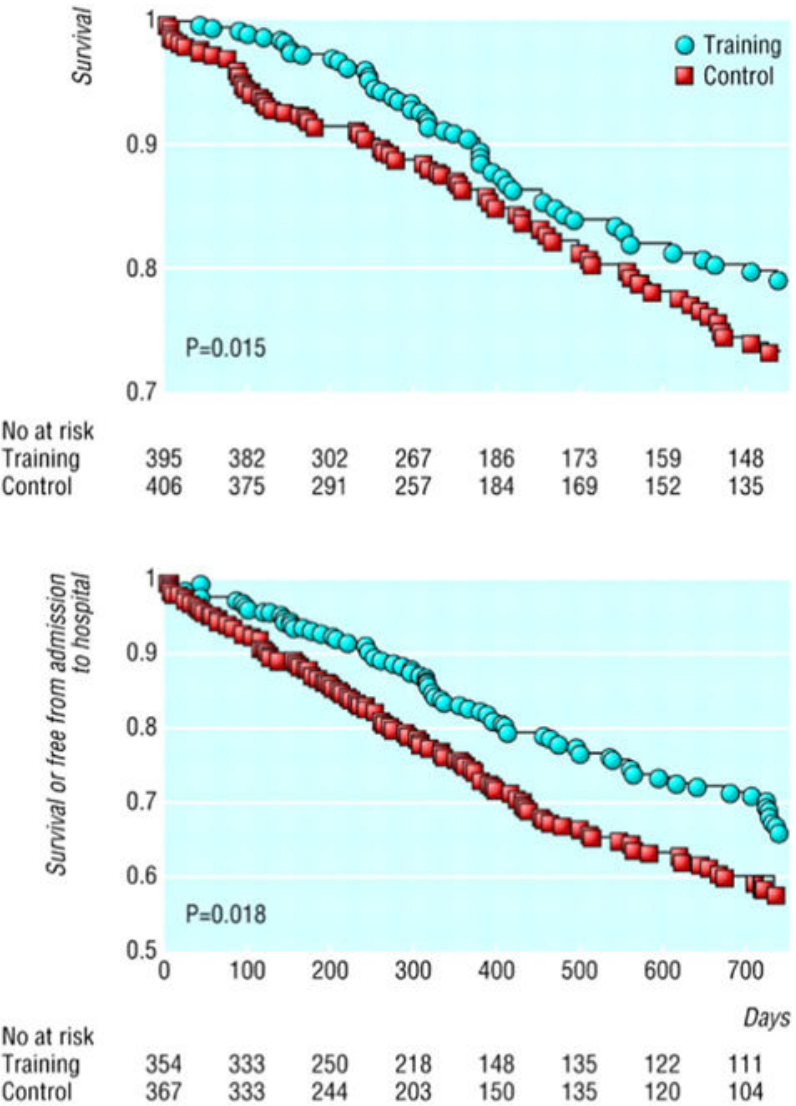

Fig. 2.

Exercise training and survival/survival or free from hospital admission in patients with chronic heart failure. (Kaplan-Meier curves demonstrating the relationship between exercise training and survival (top) and survival or free from hospital admission. Reproduced from [34].) 


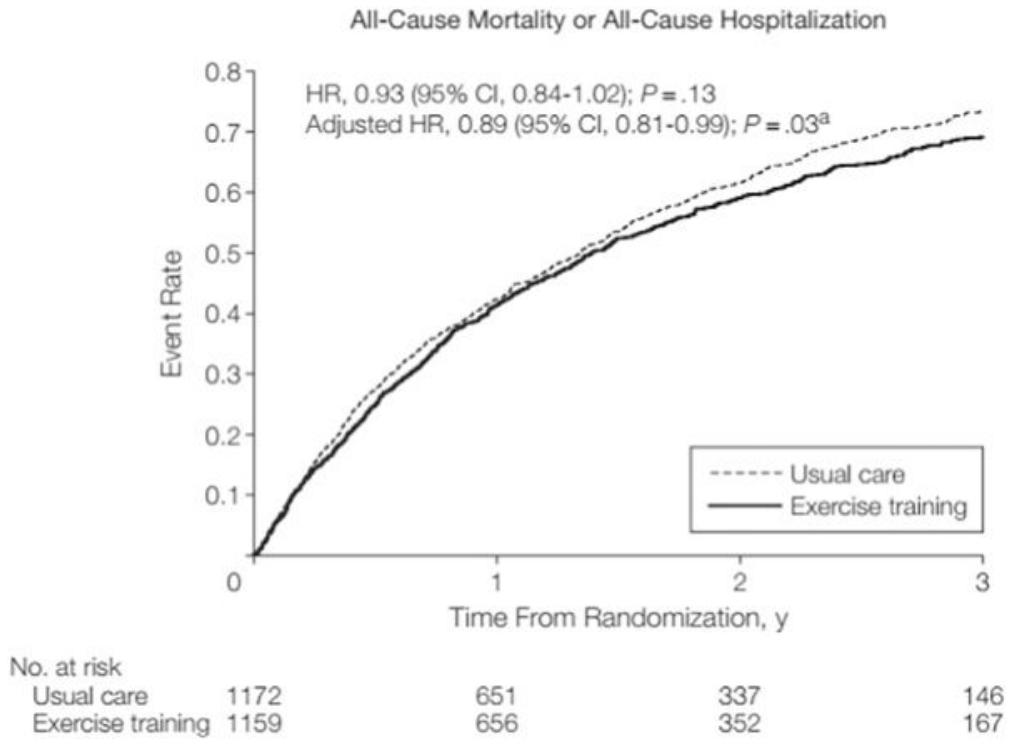

Fig. 3.

Time to All-Cause Mortality or All-Cause Hospitalization in heart failure patients. (Allcause mortality or all-cause hospitalization after adjustment for key prognostic factors. From the HF-ACTION Randomized Controlled Trial. Reproduced from [35].) 